\title{
Front-Face Fluorescence Spectroscopy and Chemometrics in Analysis of Yogurt: Rapid Analysis of Riboflavin
}

\author{
E. Miquel Becker, ${ }^{*}$ J. Christensen, † C. S. Frederiksen, ${ }^{\star}$ and V. K. Haugaard ${ }^{\star}$ \\ *Food Chemistry, Department of Dairy and Food Science, \\ The Royal Veterinary and Agricultural University, \\ Rolighedsvej 30, DK-1958 Frederiksberg C, Denmark \\ †Food Technology, Department of Dairy and Food Science, \\ The Royal Veterinary and Agricultural University, \\ Rolighedsvej 30, DK-1958 Frederiksberg C, Denmark
}

\begin{abstract}
The present study demonstrates the use of front-face fluorescence spectroscopy and chemometrics for monitoring light-induced changes in plain yogurt during storage. Fluorescence analysis is suggested as a new rapid method for measuring riboflavin content in yogurt. Fluorescence landscapes with excitation wavelengths from 270 to $550 \mathrm{~nm}$ and emission wavelengths in the range 310 to $590 \mathrm{~nm}$ were obtained from front-face fluorescence measurements directly on yogurt samples during two storage experiments over a period of $5 \mathrm{wk}$ at $4^{\circ} \mathrm{C}$. Yogurts were stored in two different packaging materials (polylactate and polystyrene) and under fluorescent light (3500 lux) or in darkness. Principal Component Analysis of unfolded fluorescence emission spectra revealed systematic changes in fluorescence signal throughout the storage period, strongly related to the storage conditions, i.e. storage time and differences in packaging materials. Correlation between fluorescence spectra and riboflavin content determined by the standard AOAC fluorometric method was evaluated using a Partial Least Square Regression model. The regression model showed a good ability to predict riboflavin in plain yogurt with a high correlation $(\mathrm{R}=0.99)$ and a prediction error of $0.092 \mu \mathrm{g}$ riboflavin/g. Thus, it is concluded that nondestructive fluorescence spectroscopy can be used to monitor riboflavin content in yogurt, and that the suggested rapid method has the potential to substitute the standard method for analysis of riboflavin in yogurt.

(Key words: fluorescence spectroscopy, chemometrics, riboflavin, yogurt, light-induced oxidation)
\end{abstract}

Abbreviation key: PCA = principal component analysis, $\mathbf{P C}=$ principal component, $\mathbf{P L S R}=$ partial least squares regression, RMSECV = root mean square error of cross validation, $\mathbf{P L A}=$ polylactate, $\mathbf{P S}=$ polystyrene .

Received December 16, 2002.

Accepted February 18, 2003.

Corresponding author: J. Christensen; e-mail: jach@kvl.dk.

\section{INTRODUCTION}

Light-induced oxidation requires the presence of a light source, a photosensitizer and oxygen in order to occur. Riboflavin plays a key role in problems related to the photosensitivity and photodegradation of milk and dairy products like yogurt. The vitamin can absorb visual light and react as a photosensitizer, which involves oxygen activation and radical formation leading to protein and lipid degradation (Skibsted, 2000). Both light and oxygen have been found to induce riboflavin degradation (Singleton et al., 1963; Sattar et al., 1977; Bosset et al., 1994; Skibsted, 2000). These oxidative deterioration processes may lead to discoloration, formation of offflavors and loss of nutrients in dairy products (Bosset and Flückinger, 1986; 1989; Bekbölet, 1990; Bosset et. al., 1994; Skibsted, 2000; Kristensen et. al., 2000). Therefore, design of packaging materials with optimal protection of the product against the combined action of light and oxygen is necessary to minimize light-induced changes.

Fluorescence spectroscopy is a rapid, nondestructive analytical technique with high sensitivity and specificity. The potential of using fluorescence in food research has increased during the last few years with the propagated application of chemometrics and with technical and optical developments of spectrofluorometers. Fluorescence spectroscopy applied on dairy products has previously been investigated in a few studies to monitor structural changes in milk proteins and their physicochemical environment during milk heating (Dufour and Riaublanc, 1997), milk coagulation (Dufour et al., 1998; Herbert et al., 1999), cheese manufacture (Dufour et al., 2001, Mazerolles et al., 2001) and in the evaluation of oxidative changes in processed cheese during storage (Christensen et al., 2002). Changes in vitamin A in dairy products have also been monitored in several fluorescence studies (Dufour et al., 2000; Herbert et al., 2000). Wold and coworkers (2002) showed that front-face fluorescence spectroscopy could be used to measure lightinduced oxidation in various dairy products, and pro- 
posed the method for rapid quantificaion of riboflavin, however, this was not verified by reference analyses. The aim of the present study is to illuminate the potential of fluorescence spectroscopy in nondestructive assessment of light-induced changes in plain yogurt.

Due to the importance on light-induced oxidation and the fact that riboflavin plays a key role in the photooxidation of dairy products, riboflavin can be considered an important marker of early oxidation in milk and dairy products. In addition, riboflavin is also an important nutrient. Therefore, a rapid analysis of riboflavin is expected to be of high interest. Riboflavin has so far been measured according to a standard fluorometric method (AOAC, 1990), which requires extraction and cleanup of riboflavin prior to the fluorometrically measurements, making the method time-consuming and the use of organic solvents necessary. The content of riboflavin is calculated by the fluorescence data recorded at one combination of excitation and emission wavelengths. In this study the potential of front-face fluorescence spectroscopy applied directly on the yogurt combined with multivariate data analysis (chemometrics) is investigated as a rapid alternative to the standard method. The proposed method offers several inherent advantages for riboflavin determination in yogurt: There is no sample preparation, since the fluorescence is recorded directly on the yogurt sample without prior riboflavin extraction. Furthermore, the whole excitation-emission matrix (fluorescence landscape) is used in the chemometric analysis and can therefore provide extra information about changes in the sample. Thus, a simultaneous analysis of more fluorescent compounds, for instance in the form of aromatic amino acids and vitamin $\mathrm{A}$, can be performed.

\section{MATERIALS AND METHODS}

\section{Yogurt and Packaging Materials}

Plain yogurt (3.5\% fat) was obtained from Arla Foods amba (Viby, Denmark). Two rigid packaging materials were used: Polylactate (PLA) cups from Autobar, France (volume $215 \mathrm{ml}$, thickness $197 \mu \mathrm{m}$, oxygen permeability $0.21 \mathrm{ml} /$ cup $\times \mathrm{d}^{-1}$ at $0.21 \mathrm{~atm} \mathrm{O}_{2}, 23^{\circ} \mathrm{C}$ and $50 \% \mathrm{RH}$ ) (Petersen et al., 2001) and polystyrene (PS) cups from Danapak Plast A/S, Denmark (volume $190 \mathrm{ml}$, thickness $244 \mu \mathrm{m}$, oxygen permeability $1.49 \mathrm{ml} /$ cup $\times \mathrm{d}^{-1}$ at 0.21 atm $\mathrm{O}_{2}, 23^{\circ} \mathrm{C}$ and $50 \% \mathrm{RH}$ ). The cups were sealed by bonding a transparent and colorless laminate from Amcor Flexible, Denmark (oxygen permeability $0.5 \mathrm{ml} /$ $\mathrm{m}^{2} \times \mathrm{d}^{-1}$ at $1 \mathrm{~atm} \mathrm{O}_{2}, 23^{\circ} \mathrm{C}$ and $5 / 95 \% \mathrm{RH}$ ) with a two component epoxy adhesive. The light transmission of the packages and the lid, as shown in Figure 1, was determined using a Cintra 40 spectrofotometer (CBC Scientific Equipment Pty Ltd, Victoria, Australia) equipped with an integrating sphere detector.

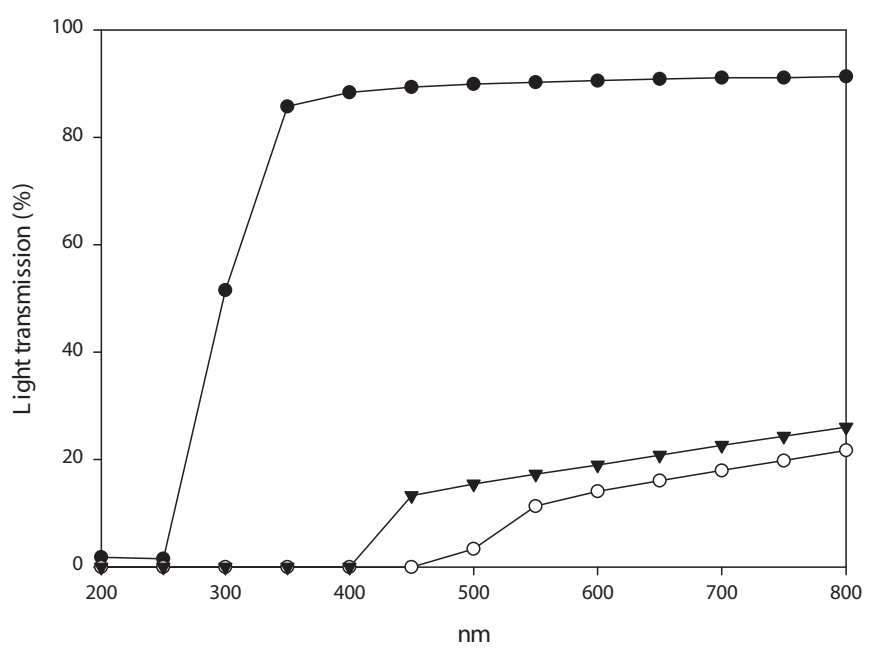

Figure 1. Light transmission spectra (\%) of PLA cups (O), PS cups $(\boldsymbol{\nabla})$ and lid $(\bullet)$.

\section{Experimental Design}

Two batches of yogurt were examined in two identical storage experiments. The amount of yogurt filled into the packages was 180 and $155 \mathrm{~g}$ for PLA and PS, respectively, resulting in a headspace volume of $35 \mathrm{ml}$ for each package. The packed samples were stored at $4^{\circ} \mathrm{C}$ for five weeks under a radiant flux of approx. 3500 lux of fluorescent light (Philips fluotone, TLD 18W/830) or in darkness. The samples stored in light were illuminated both from above through the lid and from the sides. Throughout the storage period the samples were randomly interchanged to minimize unequal temperature fluctuations and light conditions. Analyses were performed after $0,7,14,21,28$, and $35 \mathrm{~d}$ of storage, giving a total of 21 different samples ( $5 \mathrm{~d} \times 2$ light conditions $\times 2$ packaging materials + one starting sample) for each batch. Thus, 42 independent samples were studied in all. Three cups from identical conditions for each of the two batches were selected and considered as triplicates. All analyses were carried out in duplicate. Prior to the measurements, the yogurt was mixed in the cup.

\section{Fluorescence Spectroscopy}

Fluorescence landscapes were measured directly on the yogurt by filling $15 \mathrm{~g}$ of yogurt in a $30 \mathrm{ml}$ plastic cup and recording fluorescence by dipping the measuring probe $1 \mathrm{~mm}$ into the yogurt sample. All samples were measured on a BioView spectrofluorometer (Delta Light and Optics, Denmark) using a pulsed xenon lamp for excitation and equipped with an optical light conductor and a measuring probe, giving an open-end $180^{\circ}$ measuring geometry. Fluorescence landscapes were obtained 


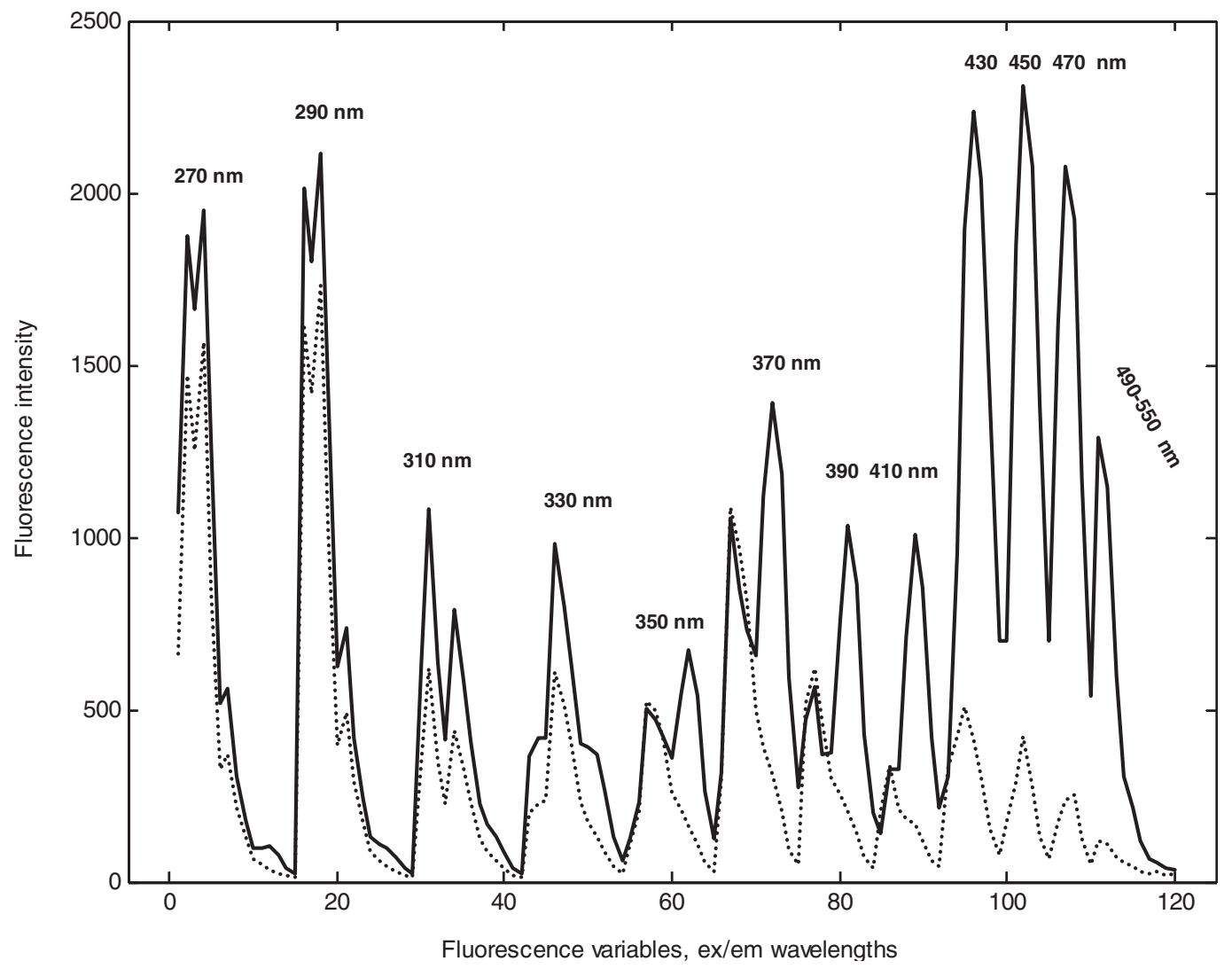

Figure 2. Unfolded fluorescence emission spectra for fresh yogurt sample (—) and yogurt sample stored in light for $35 \mathrm{~d}$ and packed in polystyrene $(\cdots)$. Excitation wavelengths are noted in top of each emission spectrum.

with excitations from 270 to $550 \mathrm{~nm}$ and emission wavelengths from 310 to $590 \mathrm{~nm}$, with intervals and bandwidths of $20 \mathrm{~nm}$, giving a total of 15 excitation and 15 emission wavelengths. Only emission wavelengths 40 $\mathrm{nm}$ above the excitation wavelength were recorded, resulting in 120 data points obtained for each measurement. For the data analysis, the 2D fluorescence landscapes were unfolded into a row of emission spectra one after another, as seen in Figure 2.

\section{Chemical Determination of Riboflavin}

The riboflavin content in the yogurt was measured by the fluorometric method established by AOAC (1990) using an Aminco Bowman series 2 luminescence spectrofotometer (SLM-Aminco, Urbana, IL). The selected wavelengths were $446 \mathrm{~nm} / 525 \mathrm{~nm}$ excitation/emission.

\section{Data Analysis}

Statistical analyses of the effects of the packaging materials, light conditions and storage time on the riboflavin content were evaluated by two-way analyses of vari- ance by the general linear model procedure (SAS, version 6.12). Significant packaging and light treatment effects were further classified by Least Significant Difference $(P \leq 0.05)$.

Principal Component Analysis (PCA), and Partial Least Squares Regression (PLSR) were the two chemometric tools used in the multivariate evaluation of the fluorescence data; both techniques based on a linear decomposition of data. PCA (Wold et al., 1987) provides an approximation of a data matrix, $\mathrm{X}$ into a few vectors, in terms of the product of two sets of vectors, $\mathrm{T}$ (scores) and $\mathrm{P}$ (loadings). These vectors capture the essential patterns of X, and are called latent variables or principal components (PC). PLSR (Martens and Naes, 1989) models the relationship between two data tables, X, and Y. PLSR is a predictive two-block regression method based on estimated latent variables and is applied to the simultaneous analysis of the two data sets, $\mathrm{X}$ (spectra) and $\mathrm{Y}$ (reference analysis).

PCA of the fluorescence data was applied in order to obtain the best possible overview of the spectral structure and distribution of samples. Score plots visualize the relationship between yogurt samples for each PC, 

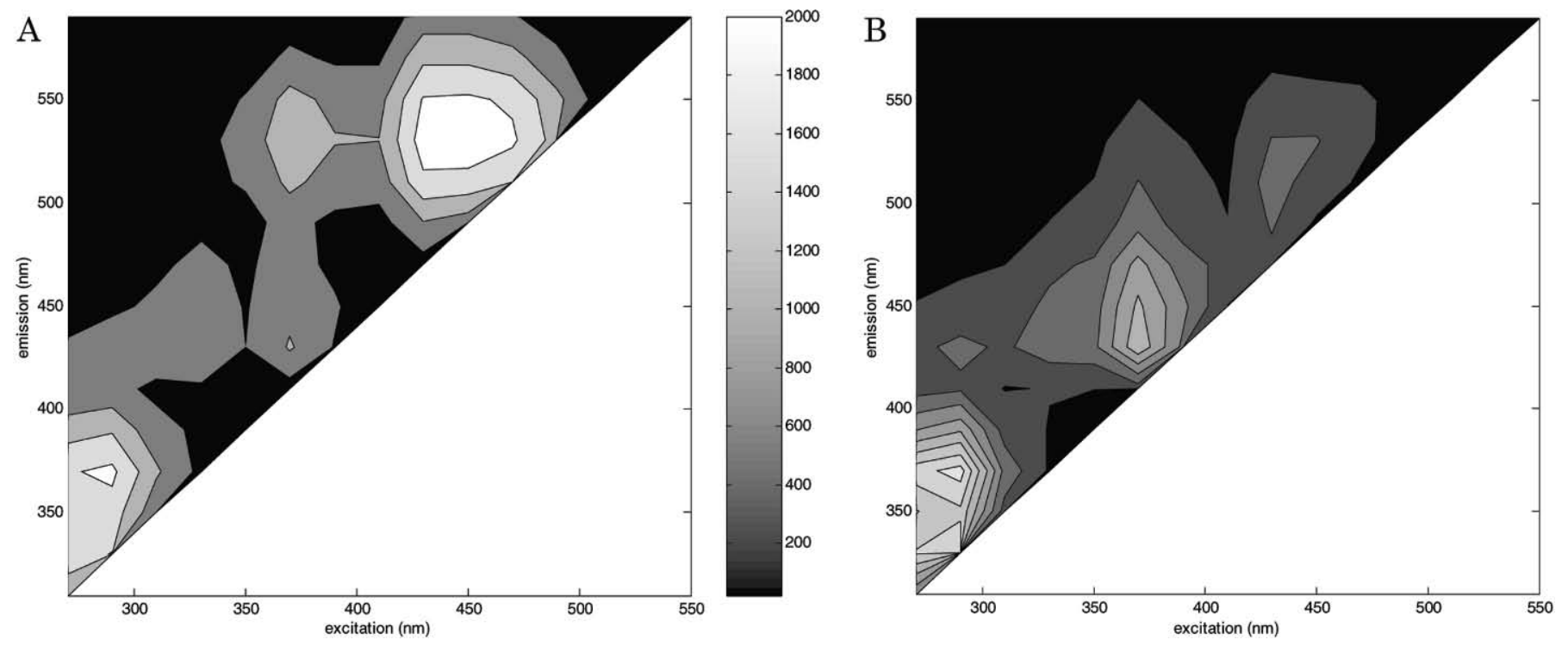

Figure 3. Contour plot of a fluorescence landscape for yogurt samples. a) fresh yogurt sample and b) yogurt sample stored in light for $35 \mathrm{~d}$ and packed in polystyrene.

while loadings plots were used for interpretation of the corresponding spectral variation. PLSR was used for investigating the dependency and making calibrations between fluorescence spectra and riboflavin content in the yogurt samples. The calibrations were performed on the average of the replicate samples. Full cross-validation was applied for all regression models. Cross-validation (Wold, 1978) is a strategy for validating calibration models based on systematically leaving out some samples in the modelling and testing them against the rest. In this case each of the samples was left out one by one, meaning that 42 submodels were calculated based on 41 samples plus one global model based on all 42 samples. For each of the models, the sample left out was predicted, and the prediction was compared with the reference values and used as a term for the validated performance of the calibration model. The regression model was evaluated using the multivariate correlation coefficient (R), and the validation parameter, Root Mean Square Error of Cross-Validation (RMSECV) as a term to indicate the error of the model. The RMSECV is defined as in equation (1):

$$
\operatorname{RMSECV}=\sqrt{\frac{\sum\left(\mathrm{y}_{\text {pred }}-\mathrm{y}_{\mathrm{ref}}\right)^{2}}{\mathrm{~N}}}
$$

where $\mathrm{y}_{\text {pred }}$ is the predicted values from the cross-validated samples, $\mathrm{y}_{\text {ref }}$ is the reference values and $\mathrm{N}$ is the number of samples.
Data analyses were performed in Unscrambler 7.6 SR1 (CAMO ASA) and MatLab 6.1 (MathWorks, Inc.) with the PLS-Toolbox 2.0 (Eigenvector Research, Inc.).

\section{RESULTS AND DISCUSSION}

The fluorescence landscapes of two yogurt samples are shown in Figure 3 in the form of contour plots. The two samples represent the extremes in the experimental plan, i.e. a fresh yogurt sample (a) and a yogurt sample stored under the most severe conditions (b). The highest fluorescence peaks for the fresh sample are seen with excitation below $300 \mathrm{~nm}$ and emission around $370 \mathrm{~nm}$ as well as for excitations between 370 to $490 \mathrm{~nm}$ and emission wavelengths around 500 to $550 \mathrm{~nm}$. The excitation and emission characteristics indicate that the fluorescence peaks arise from tryptophan (Trp) and riboflavin. Trp was reported to have excitation/emission wavelength maximum at $285 / 365 \mathrm{~nm}$ in pure solutions, and riboflavin to have emission maximum at $520 \mathrm{~nm}$ for excitations at 270, 370 and $445 \mathrm{~nm}$ (Duggan et al., 1957). The suggested Trp fluorescence still seems present in the yogurt sample stored in light for $35 \mathrm{~d}$ (Figure 3b), whereas the riboflavin signal seems considerably decreased. Thus, this experiment supports the hypothesis that photochemical degradation of riboflavin causes major changes in fluorescence. Furthermore, in Figure 3 the peak with excitation/emission maxima around 370/ $430 \mathrm{~nm}$ seems to increase during storage, and the fluorescence profile could correspond to the photo-chemical degradation product from riboflavin, lumichrome, with 


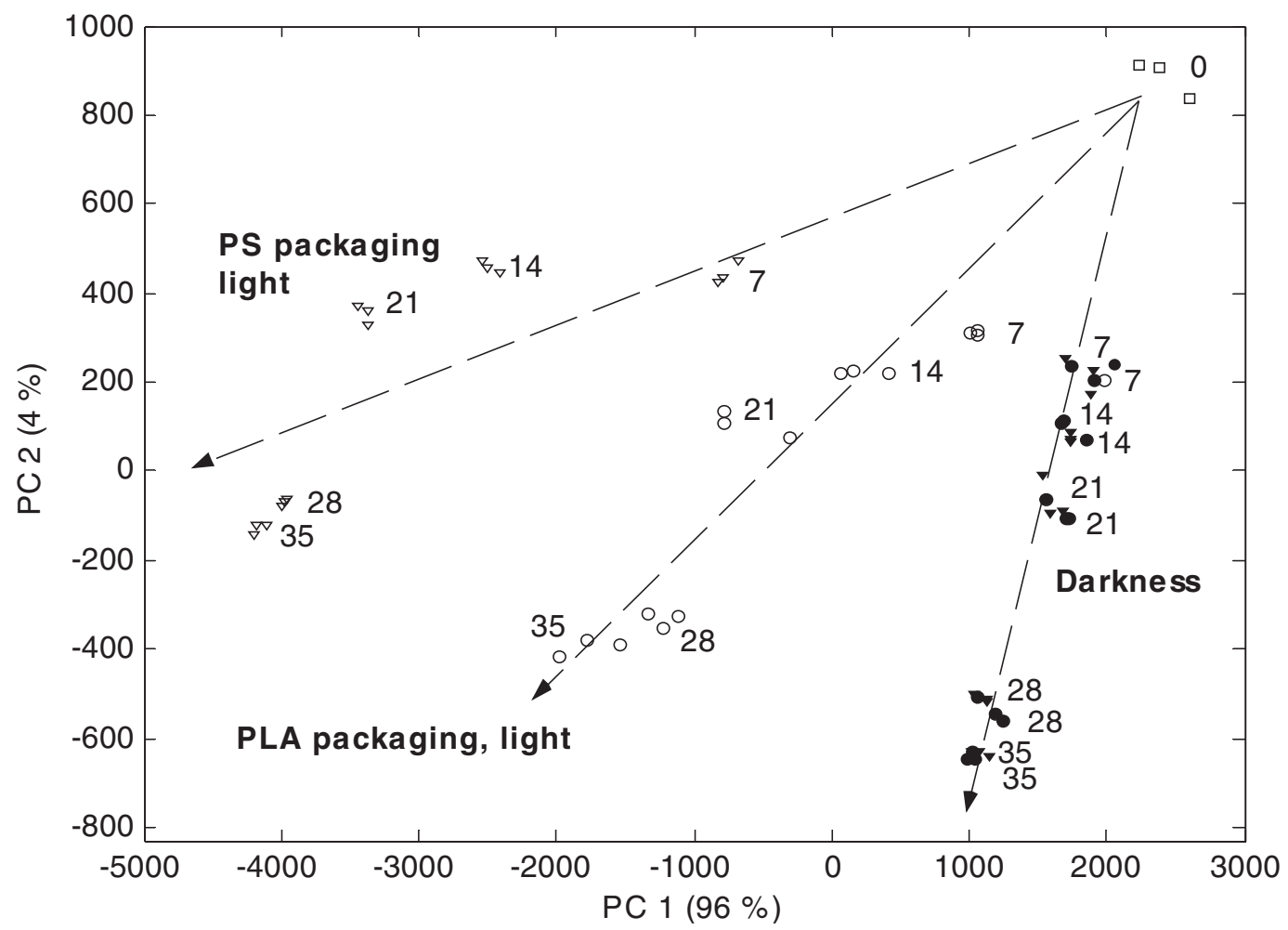

Figure 4. Score plot for PC1 vs. PC2 of a principal component analysis on unfolded fluorescence emission spectra of yogurt samples packaged in PLA $(O)$ or PS $(\nabla)$ at $4^{\circ} \mathrm{C}$ under continuous light exposure at 3500 lux (open symbol) or in darkness (dark symbol). Day 0 ( $\square$ ). Samples are numbered according to days of storage, and arrows indicate increasing storage time. Values in brackets note the degree of variation explained by each PC.

excitation/emission maxima reported somewhere around 360/450 nm in a model system (Fox and Thayer, 1998).
In Figure 2, the two same fluorescence landscapes as in Figure 3 are plotted as unfolded emission spectra in one joint plot, underlining the decrease in signal during
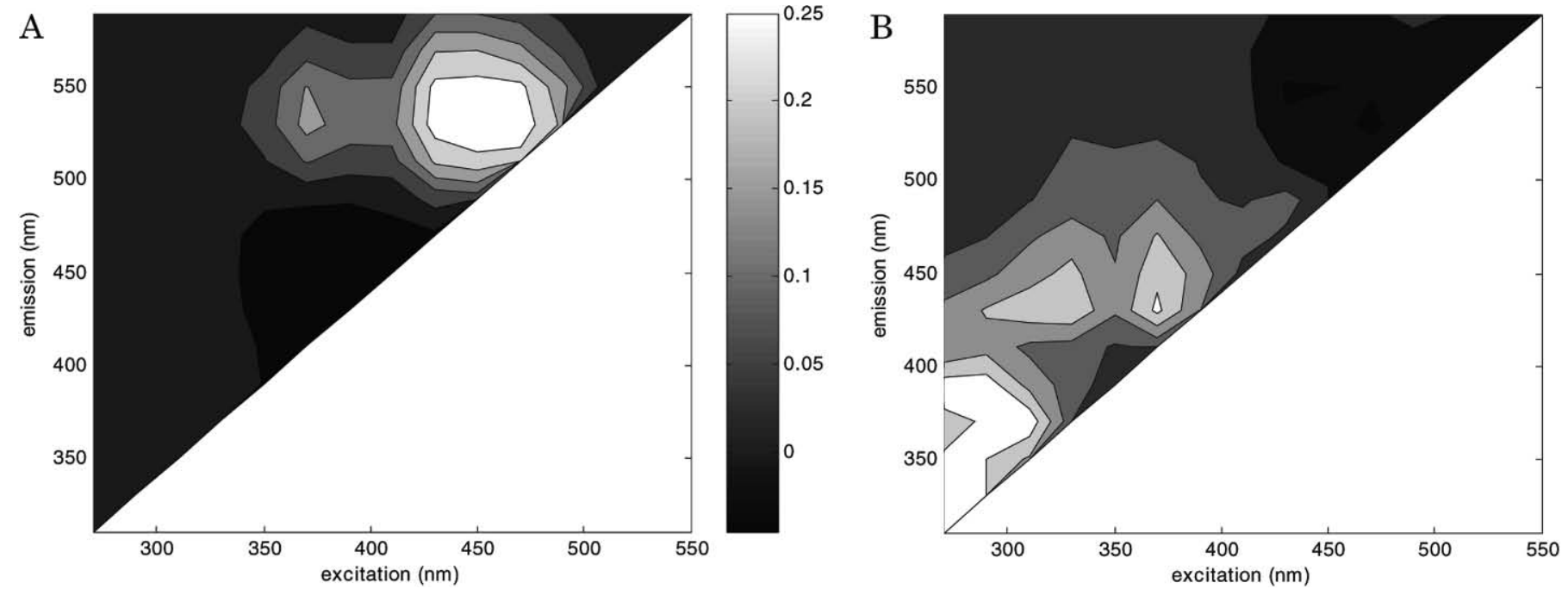

Figure 5. Contour plot of the first (a) and second (b) loading from PCA model on unfolded fluorescence emission spectra of yogurt samples. 


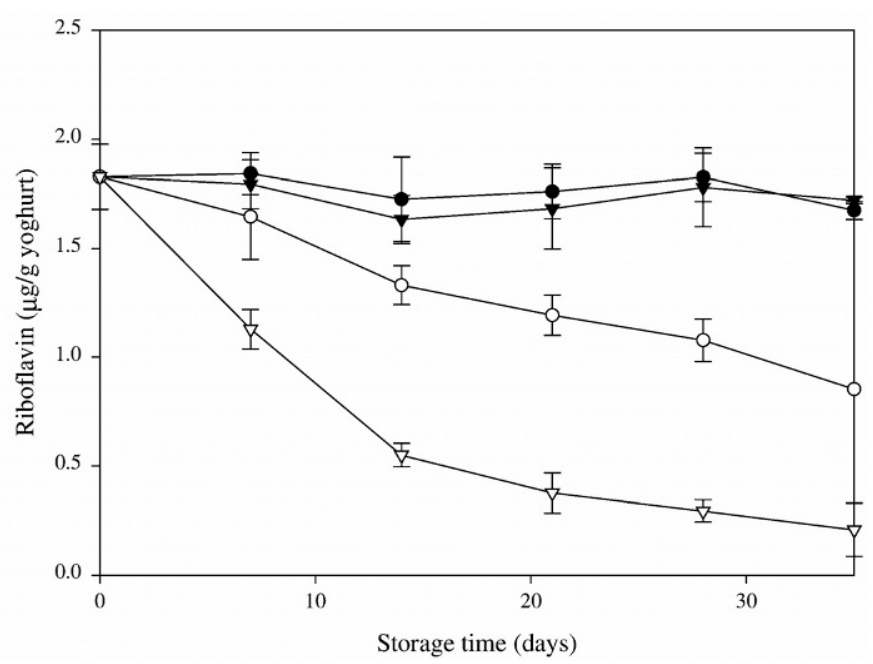

Figure 6. Riboflavin content in yogurt samples packaged in PLA $(\bigcirc)$ or PS $(\nabla)$ at $4^{\circ} \mathrm{C}$ under continuous light exposure at 3500 lux (open symbol) or in darkness (dark symbol). Bars denote the standard deviations.

storage. It also displays the way the fluorescence data is handled in the chemometric analyses, which were applied in order to further investigate the above-mentioned trend using whole fluorescence landscapes. Figure 4 shows the score plot of PC1 versus PC2 of a PCA model performed on the first storage experiment; a similar result was obtained for the second storage experiment (result not shown). The distribution of samples in the score plot clearly displays the features in the experimental design, with PC1 mainly explaining variations caused by the degree of light exposure, while PC2 seems to separate samples according to storage time, as illustrated by the arrows for each of the storage conditions (darkness, PLA, PS) and the numbers that indicate the days of storage for the given sample. Similar trends were found in the work of Wold et al. (2002), for lightexposed goat cheese and sour cream in comparison to dark storage. Differences between packaging materials are also obvious in the score plot with yogurt samples exposed to light and packed in PLA situated closer to the samples stored in darkness, in agreement with the differences between light transmission (Figure 1) and oxygen permeability of the packaging materials. Figure 5 shows the corresponding loading plot for the PCA model displaying the spectral structure of the first two PC's, in the form of refolded fluorescence spectra displayed in contour plots. The importance of the wavelengths with excitation from 370 to $470 \mathrm{~nm}$ and emission around $530 \mathrm{~nm}$ is evident in PC1 (representing 96\% of the variation), which corresponds very well with the fluorescent properties of riboflavin, indicating that the major variation in fluorescence is due to degradation of this vitamin. Furthermore a systematic negative peak with excitation/emission maxima around $370 / 450 \mathrm{~nm}$ is seen, which could be caused by formation of lumichrome throughout storage, as previously suggested. The second loading shows high values for excitation $290 \mathrm{~nm}$ and emission around $350 \mathrm{~nm}$, suggesting that this component is dominated by the variation in Trp fluorescence. However, fluorescence peaks with emission around 430 $\mathrm{nm}$ is also seen in PC2. Thus, the overall trend from the PCA is that a significant decrease in riboflavin fluorescence is observed due to light exposure throughout the storage period, and a decrease in Trp fluorescence is observed with increasing storage time, practically independent of light exposure. The spectral features found in PC1 and PC2 for excitation around $370 \mathrm{~nm}$, resembles those found by Wold et al. (2002) on various dairy products, suggesting that the proposed method can be applied to other dairy products.

The observed sample grouping in the score plot (Figure 4) of the fluorescence spectra seems to be in agreement with the chemical analysis of riboflavin (Figure 6). Continuous exposure to light resulted in a pronounced decrease in riboflavin content compared to the dark-stored yogurts. Yogurts stored in darkness showed no significant changes in riboflavin content during storage and there was no effect of the packaging materials. Yogurt exposed to light was better protected against riboflavin degradation in PLA packages than in PS packages. On d 21, 60 to $65 \%$ of the riboflavin originally present in the yogurt was retained in light-stored PLA packages, whereas only $20 \%$ was retained in yogurt packed in PS. After $21 \mathrm{~d}$ of storage there was no further decrease in riboflavin content. Similar results were obtained for the second storage experiment (result not shown). Riboflavin degradation in yogurt exposed to light was in agreement with other findings in the literature (Bosset and Flückinger, 1986, 1989).

To verify the dependency between riboflavin and fluorescence, a PLSR model was constructed with data from both storage experiments with fluorescence spectra as $\mathrm{x}$-variables and chemical analysis of riboflavin as the $\mathrm{y}$ variable. The result of the PLSR (Figure 7) underlines the strong correlation between fluorescence and riboflavin content. A multivariate correlation coefficient of $R$ $=0.99$ and a prediction error (RMSECV) of $0.092 \mu \mathrm{g}$ riboflavin/g yogurt for a 2 component model was obtained, corresponding to $7 \%$ of the mean riboflavin content in the yogurt samples. The multivariate regression was compared with a univariate one in order to investigate the advantage of the multivariate approach in the analysis of riboflavin. A linear regression model between the fluorescence data of excitation $450 \mathrm{~nm} / \mathrm{emission} 530$ $\mathrm{nm}$ and riboflavin content was constructed with identical validation conditions as for the PLSR. The univariate 


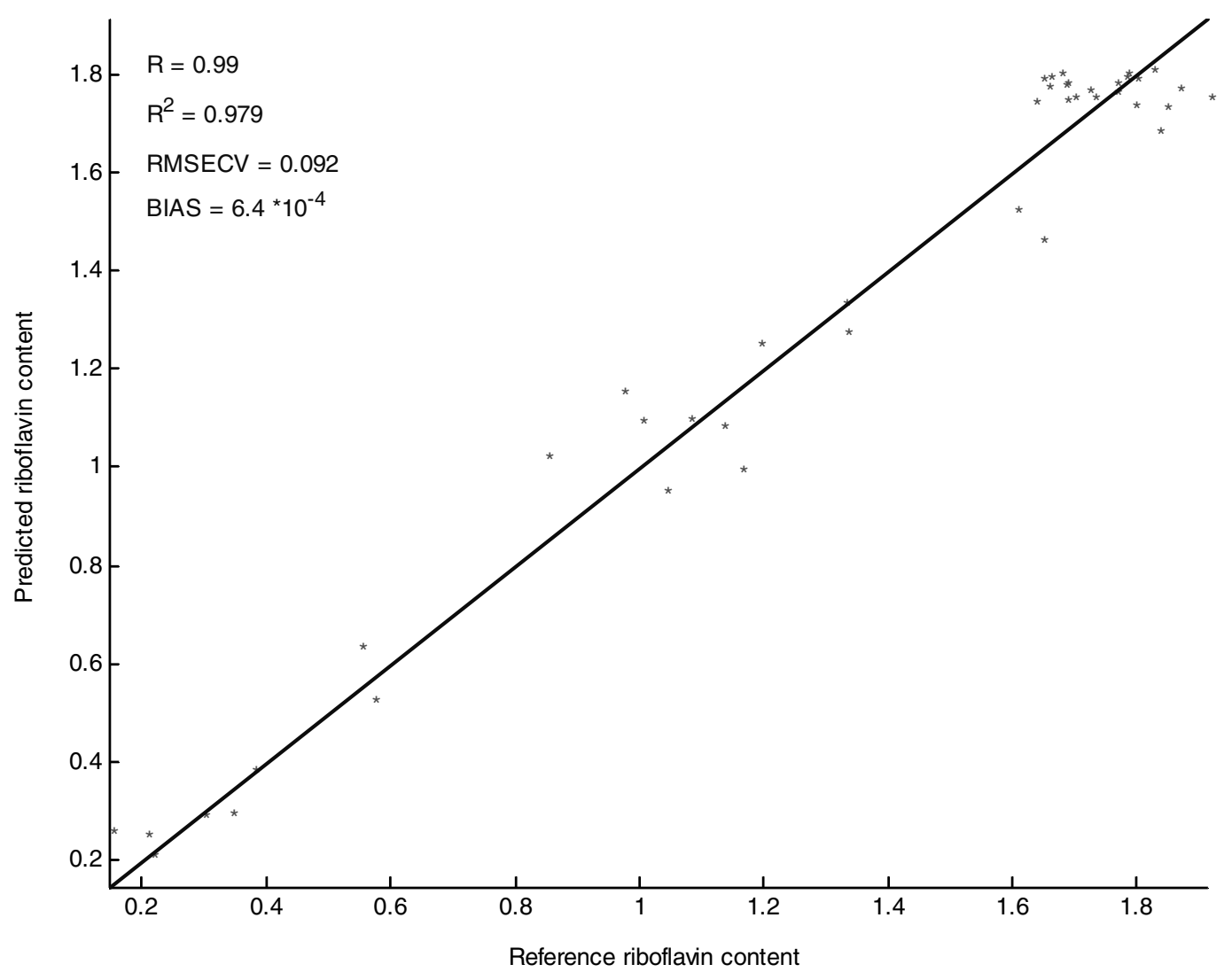

Figure 7. Predicted vs. reference riboflavin content of 42 yogurt samples, based on full cross-validation of a 2-component PLSR model on unfolded fluorescence emission spectra.

regression yielded a correlation of 0.97 and a RMSECV of $0.13 \mu \mathrm{g}$ riboflavin/g yogurt, and also proved to perform rather well for analysis of riboflavin. The multivariate regression model performed significantly better $(P=$ 0.015), when evaluated with an F-test of the RMSECV values, as suggested by Haaland and Thomas (1988). Furthermore, it is expected that a model based on the multivariate signal will be more robust against larger possible differences in the background fluorescence, and that it will improve detection of potential outliers considerably (Martens and Naes, 1989).

\section{CONCLUSIONS}

The present study demonstrates the potential of fluorescence spectroscopy and chemometrics applied for analysis of yogurt. Rapid fluorescence measurements applied directly on plain yogurt were used for monitoring degradation processes in yogurt during storage. The most important cause of changes in the obtained fluorescence landscapes was derived from riboflavin and ascribed to light-induced oxidation. It is demonstrated that the rapid fluorescence method has potential as a new rapid riboflavin analysis for yogurts. We believe that the method also has the potential for determination of riboflavin in other dairy products, but with product-dependent calibrations. However, the validity of the suggested method still remains to be tested, on a larger set of samples covering a more heterogeneous collection of yogurts.

\section{ACKNOWLEDGMENTS}

This study was partly sponsored by an EU innovation programme with the acronym OPUS (IN30905I). The aim of this project was to adapt and apply advanced fluorescence measurement techniques for online analysis to traditional food industries.

\section{REFERENCES}

Association of Official Analytical Chemists. 1990. Official Methods of Analysis. Vol. II. 15th ed. AOAC, Arlington, VA.

Bosset, J. O., and E. Flückinger. 1986. Einfluß der licht- und gasdurchlässigkeit verschiedener packungsarten auf die qualitätserhaltung von naturyogurt. Deutsch. Milchwirtsch. 29:908-914.

Bosset, J. O., and E. Flückinger. 1989. Die verpackung als mittel zur qualitätserhaltung von lebensmitteln, dargestellt am beispiel der 
lichtschutzbedürftigkeit verschiedener joghurtsorten. Lebensm. Wiss. Technol. 22(5):292-300.

Bosset, J. O., R. Sieber, and P. U. Gallman. 1994. Influence of light transmittance of packaging materials on the shelf life of milk and milk products-a review. Pages: 222-268 in Food Packaging and Preservation. Mathlouthi M. ed. Blackie Academic and Professional, Glasgow, Scotland.

Bekbölet, M. 1990. Light effects on food. J. Food Protect. 53:430-440.

Christensen, J., V. T. Povlsen, and J. Sørensen. 2002. Application of fluorescence spectroscopy and chemometrics in the evaluation of the stability of processed cheese. J. Dairy Sci. Accepted.

Dufour, E., and A. Riaublanc. 1997. Potentiality of spectroscopic methods for characterisation of dairy products. I. Front-face fluorescence study of raw, heated and homogenised milks. Lait 77:657-670.

Dufour, E., C. Lopez, A. Riaublanc, and N. Mouhous Riou. 1998. La spectroscopie de fluorescence frontale: une approche non invasive de la structure et des interactions entre constituents des aliments. Agoral 10:209-215.

Dufour, E., M. F. Devaux, and S. Herbert. 2001. Delineation of the structure of soft cheeses at the molecular level by fluorescence spectroscopy—relationship with texture. Int. Dairy J. 11:465-473.

Dufour, E., G. Mazerolles, M. F. Devaux, G. Duboz, M. H. Duployer, and N. M. Riou. 2000. Phase Transition of triglycerides during semi-hard cheese ripening. Int. Dairy J. 10:81-93.

Duggan, D. E., R. L. Bowman, B. B. Brodie, and S. Udenfriend. 1957. A spectrophotofluorometric study of compounds of biological interest. Arch. Biochem. Biophys. 68:1-14.

Fox, J. B., and D. W. Thayer. 1998. Radical oxidation of riboflavin. Internat. J. Vit. Nutr. Res. 68:174-180.

Haaland, D. M., and E. V. Thomas. 1988. Partial Least Squares Methods for Spectral Analyses. 1. Relation to Other Quantitative Calibration Methods and the Extraction of Qualitative Information. Anal. Chem. 60:1193-1202.
Herbert, S., B. Bouchet, A. Riaublanc, D. J. Gallant, and E. Dufour. 1999. Fluorescence spectroscopy investigation of acid- or rennetinduced coagulation of milk. J. Dairy Sci. 82:2056-2062.

Herbert, S., N. Mouhous Riou, M. F. Devaux, A. Riaublanc, B. Bouchet, D. J. Gallant, and E. Dufour. 2000. Monitoring the identity and structure of soft cheeses by fluorescence spectroscopy. Lait 80:621-624.

Kristensen D., V. Orlien, G. Mortensen, P. Brockhoff, and L. H. Skibsted. 2000. Light-induced oxidation in sliced havarti cheese packaged in modified atmosphere, Int. Dairy J. 10:95-103.

Martens, H., and T. Naes. 1989. Multivariate Calibration. John Wiley and Son, UK.

Mazerolles, G., M-F. Devaux, G. Duboz, M-H. Duployer, N. Mouhous Riou, and E. Dufour. 2001. Infrared and fluorescence spectroscopy for monitoring protein structure and interaction changes during cheese ripening. Lait 81:509-527.

Petersen, K., P. V. Nielsen, and M. B. Olsen. 2001. Physical and mechanical properties of biobased materials-starch, polylactate and polyhydroxybutyrate, Starch/Stärke, 53:356-361.

Sattar, A., J. M. deMan, and J. C. Alexander. 1977. Light induced degradation of vitamins. I. Kinetic studies on riboflavin decomposition in solution. Can. Inst. of Food Sci. Technol. J. 10(1):61-64.

Singleton, J. A., W. Aurand, and F. W. Lancaster. 1963. Sunlight flavor in milk. I. A study of components involved in the flavor development, J. Dairy Sci. 46(2):1051-1611.

Skibsted, L. H. 2000. Light-induced changes in dairy products. BIDFD 346:4-9.

Wold, J. P., K. Jørgensen, and F. Lundby. 2002. Nondestructive measurements of light-induced oxidation in dairy products by fluorescence spectroscopy and imaging. J. Dairy Sci. 85:1693-1704.

Wold, S., K. Esbensen, and P. Geladi. 1987. Principal Component Analysis. Chemometr. Intell. Lab. Syst. 2:37-52.

Wold, S. 1978. Cross-validatory estimation of number of components in factor and principal components models. Technometrics, 20(4):397-405. 